Lingua e Literatura, $\mathrm{n}^{\circ}$ 24. p. 131-148. 1998.

\title{
"POR QUE OS ESTRANGEIROS SĀO ESTRANHOS?" - COMO DIFERENÇAS CULTURAIS AFETAM A COMUNICAÇÃO
}

Selma Martins Meireles *

RESUMO: $O$ artigo procura ilustrar a importância de convençōes culturais que definem o estilo conversacional dos falantes de uma determinada lingua $e$ as dificuldades que podem surgir em interaçōes interculturais, mesmo quando há o domínio do vocabulário e da gramática da língua estrangeira.

Palavras-chave: interculturalidade, convençōes culturais, estilo conversacional, alemão, portuguès.

\section{A INTERCULTURALIDADE}

O jornal Folha de São Paulo de 25 de fevereiro de 1996 traz um artigo de Michael Kepp, correspondente do Brasil no jornal The Observer de Londres, intitulado "Modos brasileiros de escapar do 'não' "No artigo, o autor discorre sobre o talento dos brasileiros em "navegar em torno dos negativos " por meio de "expressōes propositadamente vagas como 'pode ser' 'vamos ver' 'se der' da qual (sic) os brasileiros diariamente se apropriam para desviar da palavra 'nāo' " Kepp, que explica ter sido "criado não no Brasil católico, mas na América protestante, onde a salvaçāo está ligada à conduta pessoal e moral rigida no cotidiano, e não na redençāo", especula que "isso ajuda a explicar porque

(*) Professora Doutora da Área de Língua e Literatura Alemã do Departamento de Letras Modernas, FFLCH-USP. 
MEIRELES, Selma Martins. "Por que os estrangeiros são estranhos?" como diferenças culturais afetam a comunicação

os americanos são muito mais bruscos que os brasileiros, que sāo mais corteses. É por isso que os brasileiros nos chamam de 'objetivos', para nāo dizerem que somos grosseiros."

Tais considerações sobre diferenças culturais a respeito de 'cortesia' ou 'grosseria' no que se refere aos modos de expressāo, nāo constituem novidade para estudiosos ou para leigos, pois o contato entre culturas diferentes sempre leva a uma comparação, a qual inevitavelmente é centrada nos valores próprios de cada cultura, gerando juízos como: "tal povo é gentil/grosseiro/trabalhador/preguiçoso, etc." Tal comparação é a raiz dos preconceitos e, embora seja condenada com horror pelos politicamente corretos de todo o mundo, nada pode ser feito para refreála, pois, a partir do momento em que o individuo toma consciência de seu ego como distinto daquele do outro, a comparação centrada no modelo próprio e o juízo de valores sāo inevitáveis. Além do mais, nāo se pode negar que, se tais contrastes sāo sentidos por vários membros de uma mesma cultura, eles realmente existem e nāo podem ser simplesmente descartados como invençōes de individuos preconceituosos.

Contatos entre individuos de diversas culturas sempre foram sentidos como difíceis, mas tal dificuldade costuma ser considerada como restrita à barreira da língua. Contudo, cada vez mais pesquisadores concluem que essa é apenas a primeira barreira a ser vencida, e que os contatos com o "estranho" e o "estrangeiro" desencadeiam em cada um dos participantes deste contato um processo que ao mesmo tempo marca os contrastes e busca interpretálos adequadamente. Em um artigo de 1997 Dornbusch remete às ideias de Todorov sobre as etapas que caracterizam o processo de compreensāo do outro: em uma primeira fase, o individuo percebe e analisa o outro (no nosso caso, um membro de outra cultura) com base em sua própria identidade; na segunda fase, o individuo procura anu- 
lar-se e identificar-se com a outra cultura, tentando analisála mais objetivamente. Em uma terceira fase, susbtitui-se a dualidade pela multiplicidade: os valores do outro sāo percebidos como sendo tão relativos quanto os próprios. Finalmente, o individuo, modificado pelo encontro e pela percepçāo de uma outra cultura, reconstrói a sua identidade, diferente da que possuía inicialmente e não anulada pela identidade do outro (cf. Dornbusch, 1998, 16ss.).

Tais constatações têm levado a estudos que, atualmente, recebem na Alemanha a rubrica de estudos da interculturalidade. O termo é usado de maneira bastante imprecisa e já conta com muitos descrédulos, que o acusam de ser um "termo guarda-chuva" para qualquer evento que envolva mais de uma cultura. No entanto, acredito que a base da idéia dos estudos interculturais é válida: observar a própria cultura em pé de igualdade frente às demais, não a considerando nem superior (com a conseqüente rejeição e valoração negativa própria dos xenófobos) nem inferior às outras (evitando as atitudes de "povos colonizados" que se sentem culturalmente inferiores frente a outras culturas e que acreditam que "tudo o que vem de fora é melhor"). Tal perspectiva permitiria uma análise mais neutra das razōes das diversas convenções e visões de mundo que caracterizam os vários grupos culturais, contribuindo para o respeito e compreensão mútuos em situaçōes de encontros de individuos pertencentes a grupos diferentes. Na Alemanha, utiliza-se muito neste contexto a palavra "tolerância" mas eu a julgo inadequada para expressar o que se espera atingir nos estudos interculturais: por "tolerância" entendo uma atitude de permissão, mais ou menos irritadiça, frente a um comportamento que é julgado inadequado ou estranho. "Respeito", no entanto, parece-me traduzir a postura de constatação de uma diferença, sem julgamentos, e a disposição de permitir que a mesma se mantenha como uma opção válida, que, no entanto, não é preciso seguir ou evitar. 
134 MEIRELES, Selma Martins. "Por que os estrangeiros são estranhos?" como diferenças culturais afetam a comunicaçāo

Dentre os vários temas abordados pelos estudos da interculturalidade, estão as interaçōes lingüisticas entre membros de grupos culturais diferentes, em especial, aqueles que falam linguas diversas. Por um longo tempo, pensou-se que o aprendizado puro e simples do vocabulário e das regras gramaticais de uma lingua estrangeira bastaria para garantir uma comunicaçāo bem sucedida com falantes dessa língua. No entanto, tal não acontece. Vários pesquisadores têm chamado a atenção para o fato de que outros fatores têm também grande influência na comunicação intercultural. Neste artigo, procurarei ilustrar a importância de tais fatores citando alguns trabalhos sobre o tema e através da apresentaçāo de exemplos ilustrativos, baseados principalmente na minha área de atuação como professora de alemão como lingua estrangeira.

Como pano de fundo para demonstrar a importância da atuação de fatores culturais sobre a expressão lingüistica, apresentarei algumas reflexōes básicas sobre o tema, constantes principalmente de um artigo de John J. Gumperz e Jenny Cook-Gumperz na obra Language and social identity (1982), os quais partem do pressuposto de que a comunicação é muito mais fácil entre individuos que têm um background comum. Isso pode ser facilmente percebido ainda dentro de uma mesma cultura: pessoas que pertencem à mesma profissão, ou instituição, ou mesmo que viveram próximas por um longo tempo, como marido e mulher ou amigos próximos, comunicam-se facilmente e estão menos sujeitos a problemas oriundos de mal-entendidos. No entanto, os autores ressaltam que, quando os backgrounds são diferentes, principalmente entre pessoas de nacionalidades/ culturas diversas,

os encontros podem ser atormentados por mal-entendidos, falhas de interpretaçāo mútuas e avaliaçōes errôneas de eventos... estratégias de persuasão e argumentaçāo aceitas tacitamente podem deixar de ser bem sucedidas. Mais, as dificuldades que ocorrem 
em tais situaçōes não desaparecem com uma maior intensidade de contato intergrupal. Pelo contrário, elas parecem aumentar e geralmente tornam-se mais agudas com o passar do tempo, quando as dificuldades iniciais com a gramática já desapareceram. Guando essa situaçāo persiste através dos tempos, o que começou como uma diferença comunicativa ligada a uma situaçāo isolada entre individuos pode fossilizar-se em distinçōes ideológicas que recebem uma determinada valoraçāo, de modo que, cada vez que surgem problemas de entendimento, elas ajudam a criar maiores diferenças na simbolizaçāo da identidade. (Gumperz \& Cook-Gumperz, 1982, p. $2 s.)^{1}$

Tal problema é também apontado por Ehlich, que ressalta a importância de fatores outros que o domínio do vocabulário e da estrutura de uma lingua estrangeira para a boa comunicaçāo intercultural, e como o dominio desses elementos apenas acentua a sua falta quanto a outros fatores envolvidos: conforme o aprendiz aperfeiçoa-se na língua estrangeira, os enunciados e atitudes anômalas tornam-se cada vez mais esporádicos e, exatamente por isso, ganham uma nova dimensāo na interaçāo com os membros da cultura estrangeira. Dominando a língua do grupo, o falante estrangeiro é aceito como um de seus membros, desarmando os mecanismos de proteção e tolerância. Os enunciados e atitudes anômalas passam entāo a ser vistos como quebra das expectativas do grupo, as quais estão na base do entendimento e da confiança mútuos, podendo inclusive ser interpretadas como provocação ou outras atitudes semelhantes (cf. Ehlich, 1986, p. 50).

Tais problemas de transferência de padrōes culturais deveriam ser estudados juntamente com os problemas de interferência, isto é, a tendência de aprendizes de uma lingua estrangeira de transferir padrōes de sua lingua materna para a segunda língua. No entanto, até há pouco

(1) As traduçōes das citações provenientes de obras escritas em inglês e alemão são de minha autoria. 
tempo, os estudos sobre problemas causados por interferência do padrão comunicativo materno têm sido concentrados na fonologia e gramática de sentenças isoladas, não levando em conta as conseqüencias comunicativas. Um exemplo de transferência de padrōes culturais que se sobrepõem a um domínio perfeito da língua foi-me narrado recentemente por uma colega da FFLCH/USP: uma conhecida sua, espanhola de nascimento, vive há muito tempo no Brasil. Novamente na Espanha, foi à farmácia comprar alguns curativos e, ao interpelar a atendente, utilizou o correspondente em espanhol a uma frase como "a senhora por acaso teria curativos?" A atendente reagiu furiosamente, perguntando por que não haveria de tê-los, já que aquilo era uma farmácia. A frase estava perfeita para os padrōes gramaticais e entonatórios espanhóis, mas estava pragmaticamente inadequada para aquela situação naquela cultura. $O$ que seria muito educado no Brasil pareceu irônico na Espanha.

\section{EXEMPLOS DE MAL-ENTENDIDOS CAUSADOS POR DIFERENÇAS CULTURAIS}

Gumperz \& Cook-Gumperz argumentam que a identidade social e étnica são em grande parte estabelecidas e mantidas através da linguagem. Assim, em uma interação lingüistica, falantes de diferentes backgrounds culturais utilizam-se inconscientemente de estratégias distintas de uso da linguagem e de retórica. Quando isso ocorre, é comum que diferenças na interpretação de tais estratégias afetem o resultado de um encontro, como vimos no exemplo anterior. Os autores afirmam que "mesmo uma palavra ou expressão estranha ou um tom de voz mal interpretado podem afetar seriamente a confiança entre os participantes de uma interaçāo" (Gumperz \& Cook-Gumperz, 1982, p. 8). Vários desses casos têm sido relatados em pesquisas sobre interaçōes interculturais. Como ilustração, gostaria de citar dois exemplos colhidos dessa literatura. 
Primeiramente, há o caso de um restaurante na Inglaterra que tinha problemas com seus garçons paquistaneses, porque estes eram considerados grosseiros pelos clientes ingleses. No entanto, os mesmos empregados eram considerados gentis pelos clientes paquistaneses. Durante uma investigação etnolingüística, descobriu-se que os clientes ingleses achavam os paquistaneses rudes quando eles faziam perguntas aos clientes, como, por exemplo, que tipo de molho eles queriam. Descobriu-se, então, que os ingleses esperam, em tais situações (perguntas), uma curva entonatória diferente daquela utilizada pelos paquistaneses, provavelmente sob influência de sua língua materna, o que criava nos ingleses uma impressão de desinteresse e rudeza.

Um caso semelhante ocorreu com uma estudante chinesa na Alemanha, que também era considerada rude e mal-humorada por seus colegas alemães. Ela morava em um conjunto residencial estudantil, que tinha um telefone comum a todos os moradores do andar. É costume que qualquer morador do andar atenda ao telefone e chame o destinatário do telefonema mais ou menos desta maneira: "Fulano, telefone!" No entanto, a curva entonatória dessa frase é bastante marcada e convencionalizada, quase musical, alongando as silabas "te" e "fon" e terminando de forma ascendente. A estudante chinesa, devido em parte à sua dificuldade com a língua, não seguia tal melodia e ainda utilizava uma curva descendente, o que era interpretado pelos alemães como irritação pelo fato de haver atendido a uma chamada que não era para ela.

\section{ESTILO CONVERSACIONAL E A CRIAÇÃO DE ESTEREÓTIPOS}

É desnecessário frisar a importância da conscientizaçāo de que fatores culturais são decisivos no que se refere às convençōes válidas para a formulação e apresenta- 
ção de conteúdos. Após os exemplos apresentados, fica clara a responsabilidade, por exemplo, dos intérpretes que atuam em missões diplomáticas ou negociaçōes envolvendo parceiros multinacionais. A eles cabe não somente a tarefa de verter conteúdos em formas lingüisticas equivalentes na lingua estrangeira, mas também de "interpretar" o que se quis transmitir juntamente com tais formulaçōes lingüísticas.

Os exemplos citados anteriormente também ilustram bem a necessidade de considerar, além do léxico e da gramática, outras "pistas" lingüísticas que sinalizam informaçōes relevantes em uma interação, como prosódia, pausas, idiomatismos e outras expressōes convencionalizadas, os quais, em conjunto, formam o que Gumperz \& Cook-Gumperz, entre outros, denominam estilo conversacional. Os autores afirmam que, na conversação, comunicamos simultaneamente um conteúdo e nossa atitude frente a ele (cf. op.cit., p.13). Tal fato fica bastante claro quando se pensa nas considerações de Sperber \& Wilson (1986) sobre a noçāo de Relevância em situações comunicativas: se um falante diz algo de uma determinada maneira, seu interlocutor procurará atribuir relevância e, por conseguinte, significado, a qualquer comportamento que ele julgue estar fora dos padrões de neutralidade frente à situação e ao tema da interação.

De acordo com diferentes socializações em diferentes culturas, a noção do que é "neutro" em termos de relevância pode variar muito. A assunção básica é de que algo está sendo comunicado. O problema é como interpretá-lo. Onde os padrōes divergem, como em vários casos de comunicaçāo intercultural, as convençōes diferem e a comunicação pode falhar. Gumperz \& Cook-Gumperz alertam para o fato de que 
de uma outra pessoa de acordo com suas próprias convençōes. Isto significa que alguém pode fazer inferências totalmente equivocadas sobre outra pessoa. Por exemplo, ele/a pode concluir que alguém está sendo rude, irrelevante, chato ou simplesmente náo fazendo sentido algum. (op.cit., p.18)

Um dos aspectos deste problema que tem merecido muita atençāo na literatura sobre o assunto é o problema da polidez e seus efeitos sobre a escolha de quais informaçōes são enfatizadas e quais são deixadas implicitas em determinadas situações. Trabalhos como os de Tannen (1986), Young (1986) e Günthner (1993), entre outros, ilustram como a expectativa de uma expressão mais ou menos direta entre os participantes de uma comunicação intercultural pode gerar problemas. Tannen examina diferentes interpretaçōes de afirmações por parte de americanos e gregos, concluindo que os americanos preferem expressar-se de modo mais direto e não procuram por interpretaçōes baseadas em detalhes como maior ou menor demonstração de entusiasmo através da entonação, por exemplo, o que pode levar a deficiências na comunicação entre falantes das duas culturas. Young mostra como as diferenças nas normas de polidez entre chineses e americanos podem resultar em má-comunicação, ao examinar as diferentes avaliaçōes da melhor maneira de apresentar um pedido: americanos fazem o pedido diretamente e em seguida apresentam razões que o justificam. Falantes chineses, por outro lado, consideram tal estratégia tremendamente rude e perigosa, por implicar que o falante tenta impor sua vontade aos demais. Para os chineses, é necessário primeiro listar as razões que os levaram a fazer tal pedido, para que o próprio interlocutor conclua que o pedido é decorrente das circunstâncias. A impressão resultante é de insegurança e falta de convicção, por um lado, e o de rudeza e falta de consideraçāo frente aos demais, do outro. O mesmo acontece em interaçōes envolvendo chi- 
neses e alemães, conforme a obra de Günthner: os alemães consideram os chineses como dissimulados e sem opinião própria, sempre prontos a concordar com o interlocutor; os chineses, por sua vez, aterrorizam-se com a "agressividade" dos alemães e com a sua falta de tato para questōes pessoais. Novamente, diferentes convençōes culturais sobre o que deve ser ou não tematizado e quando fazê-lo levam a mal-entendidos e à criação de estereôtipos e preconceitos.

\section{AS DIFERENÇAS BATEM À NOSSA PORTA}

Pelos exemplos apresentados, poderiamos supor que tais divergências culturais se restringissem a interaçōes entre falantes de culturas ocidentais e orientais. Isto não é verdade. Apenas, por estarmos fortemente conscientes das grandes diferenças culturais entre Oriente e Ocidente, temos maior tendência a interpretar problemas de comunicação como decorrentes de diferentes socializações. Mas isto ocorre também entre culturas de cada um dos grandes blocos. Podemos, aqui, voltar ao exemplo mencionado no início deste trabalho: o artigo do jornalista americano é mais uma excelente ilustração de que a maneira como as pessoas se expressam lingüisticamente, com muita freqüência, é considerada como expressão de seu caráter. $\mathrm{O}$ autor do artigo detecta um ponto de divergência lingüistico entre sua cultura e a brasileira, quando afirma que falantes brasileiros evitam utilizar-se de elementos negativos nas interações. O jornalista busca então as razões de tal divergência na socialização dos dois povos e especula que a origem dessa aparente "objetividade maior" dos americanos frente aos brasileiros (ambos moldados fortemente pela cultura ocidental européia) talvez esteja na grande influência do protestantismo na formação dos primeiros, a qual influenciaria seu modo de expressāo. 
Porém, mesmo entre comunidades da mesma orientação religiosa ocorrem choques culturais. O mesmo choque vivenciado pelo jornalista, entre "brasileiros corteses/americanos rudes" repete-se quando alemães interagem com americanos, porém, com a diferença que a dicotomia formada consiste de "americanos corteses/alemães rudes" conforme demonstram vários estudos (cf. House, 1979; House/Kasper, 1981; Byrnes, 1986 e Kotthoff, 1989 e 1989(a), entre outros), ainda que ambas as culturas sejam predominantemente protestantes. Alemães assumem também o pólo "rude" frente a outras culturas (cf., por exemplo, Genzmer, 1987 e Günthner, 1993), sendo que isto normalmente é creditado ao fato de os alemães serem considerados por demais diretos e incisivos.

Tal "franqueza total" parece ser admitida e cultivada pelos próprios alemães, que freqüentemente citam as palavras de Goethe: im Deutschen lügt man, wenn man höflich ist ("em alemão, mente-se quando se é gentil" - Faust, Ato 2). No entanto, isto não significa que os alemães não conheçam a polidez. Vários estudos mostram o contrário, inclusive o de Weinrich (1986), que contextualiza e desmistifica a citação de Goethe. A sensação de desconforto surge do uso de diferentes Estratégias de Trabalho da Face ${ }^{2}$ em contextos diversos, em cada cultura.

O estudo de Kotthoff (1989), sobre diferenças culturais entre alemães e americanos que influenciam na comunicação intercultural, analisa diversos contextos nos quais não se esperaria esse tipo de problemas: entre eles estão os cumprimentos. Falantes alemães demoram a compreender que a pergunta how are you? não requer uma resposta completa e sincera, como em alemão, mas ape-

(2) O termo "polidez" é comumente empregado na literatura para designar comportamentos que têm por finalidade o estabelecimento e manutenção das relaçōes entre os participantes de uma interação. Por considerar que este termo evoca conotações que nāo sāo sempre válidas quando se investiga cientificamente tais processos, prefiro o termo Trabalho da Face que utilizo em minha tese de doutorado, com base nos trabalhos de Goffman $\mathrm{e}$ Brown \& Levinson (vide Meireles, 1997). 
142 MEIRELES, Selma Martins. "Por que os estrangeiros sāo estranhos?" como diferenças culturais afetam a comunicação

nas a repetição da pergunta. Descobrem também, a duras penas, que ao encontrar um amigo nāo devem queixar-se ou e falar sobre coisas desagradáveis, embora isso seja comum na Alemanha. Outra fonte de problemas são situaçōes de despedidas: quando hóspedes americanos manifestam o desejo de se retirar, anfitriōes americanos agradecem que as visitas tenham se dado ao trabalho de visitálos, mesmo que por pouco tempo. Anfitriōes alemães na mesma situação, por outro lado, insistem para que as visitas fiquem mais um pouco, o que causa irritação a convidados americanos, porque lhes dá a impressão que os anfitriões não se importam com suas vontades. Kotthoff alerta para o fato de que, entre alemāes, o hóspede deve mostrar claramente seu desejo de sair imediatamente, caso contrário, estará apenas sinalizando que deve partir dentro de algum tempo.

Cumprimentos e elogios também são fontes de malentendidos: americanos parecem ser mais pródigos e efusivos em seus elogios que os alemāes. Conseqüentemente, o que os alemāes interpretam como grande entusiasmo por parte dos interlocutores americanos, realmente não existe, trazendo mais tarde uma grande frustração. A autora relata um experimento, no qual falantes de ambas as culturas deviam expressar-se sobre um pulover que um amigo/a havia tricotado e que não havia ficado muito bom. A maioria dos alemães não fez qualquer elogio e alguns ainda incluiram alguma critica. Os americanos, por outro lado, sempre procuravam por algum ponto positivo que pudessem ressaltar evitando as criticas. Indagados pelas razōes de tal procedimento, os falantes alemães justificaram-se com base em seu senso de honestidade, enquanto os americanos julgavam mais importante evitar o desapontamento da pessoa. O mesmo acontece em relação às criticas: em alemāo, são diretas e consideradas construtivas, enquanto americanos optam por acentuar primeiramente possiveis aspectos positivos para suavizá-las. 
Ainda um outro ponto é a questão das discussões e debates: entre os alemães, discussōes calorosas são vistas como um passatempo agradável entre amigos, enquanto americanos, nas mesmas situações, evitam prender-se a um tema ou demonstrar desacordo veementemente.

Uma diferença de convençōes culturais que costuma causar muitos problemas a estudantes alemães e americanos que estudam fora de seus paises é o da elaboração de seminários e textos científicos: em textos americanos, a argumentação tende a ser bastante linear e breve, enquanto os alemães tendem a ser mais digressivos. Assim, professores americanos freqüentemente perdem a paciência com estudantes alemães, que "jamais dizem a que vêm" enquanto professores alemães tendem a considerar os textos de estudantes americanos como superficiais e pouco elaborados. Tais diferenças culturais quanto às expectativas de elaboração desse tipo de textos têm grande importância, quando se considera que as notas e conseqüentemente o sucesso nos estudos dependem delas. No Brasil, tive várias oportunidades de vivenciar tal conflito de expectativas, ao participar de comissōes avaliadoras da prova oral dos certificados de proficiência em lingua alemã, quando as argumentaçōes de alunos brasileiros são freqüentemente consideradas deficientes por não seguirem o modelo alemão.

\section{UM PEQUENO EXEMPLO DE DIVERGÊNCIAS ENTRE BRASILEIROS E ALEMÃES}

O estilo de argumentação não é o único ponto de divergência culturalmente definida entre brasileiros e alemães. Retomando ainda uma vez o exemplo citado no início deste artigo, é interessante notar que o jornalista americano tenha escolhido exatamente a aparente relutância de falantes brasileiros utilizarem-se de expressões negativas como ponto de partida para suas reflexōes sobre uma 
144 MEIRELES, Selma Martins. "Por que os estrangeiros são estranhos?" como diferenças culturais afetam a comunicação

suposta dificuldade de assumir compromissos e posiçōes, pois exatamente essa "queixa" é freqüentemente expressa por falantes alemāes com relaçāo a brasileiros, dando origem ao mesmo tipo de valoraçāo sobre "brasileiros corteses/dissimulados" frente a "alemães diretos/grosseiros"

A constatação de tal conflito levou-me a abordar um de seus aspectos em minha dissertação de mestrado, na qual analisei o uso de elementos sintáticos negativos em diálogos das duas línguas. Este trabalho levou à conclusão de que falantes alemães e brasileiros utilizam-se de elementos sintáticos negativos com a mesma frequiência de ocorrência, mas não nas mesmas situaçōes de comunicação:

A análise dos dados obtidos mostrou que a primeira grande divergência no uso da NEGAÇÁo em ambas as línguas é na realidade semântico-pragmática, sendo que falantes brasileiros parecem subtilizar elementos sintáticos negativos em categorias semânticas de negação que implicam contestação da ilocução ou do valor de verdade de conteúdos apresentados pelo interlocutor. (Meireles, 1991, p. 141)

Através das pesquisas para a dissertaçāo de mestrado, desenvolvi um grande interesse pela diferença de freqüência de uso de elementos sintáticos negativos nas categorias que implicam discordância com o interlocutor, ou Dissensão, em ambas as linguas. Se não há razōes porque brasileiros devam expressar menos sua Dissensão que os alemães, haveria a possibilidade de uma preferência dos brasileiros por uma Dissensão menos explicita, devida a diferentes regras culturais e visando a minimizar a possibilidade de conflitos, como sugerido no artigo do jornalista americano?

Uma resposta definitiva a essas indagaçōes, por sua complexidade e abrangência, demandará ainda muitos estudos. O primeiro passo nessa direção consiste no estudo da expressão lingüística da Dissensão entre falantes de uma 
mesma comunidade e das Estratégias de Trabalho da Face mais utilizadas em cada cultura, que servirá de base para posteriores estudos e especulações. Em minha tese de doutorado centrei-me, portanto, no estudo da expressão da Dissensão em diálogos falados do Alemão. Posteriormente, pretendo desenvolver outros estudos correspondentes em diálogos do Português, para depois proceder a estudos comparativos que possam fornecer um panorama das possiveis semelhanças e diferenças do uso de Estratégias de Trabalho da Face em situaçōes de Dissensão.

Este é apenas um dos inúmeros estudos que poderiam ser feitos no campo dos estudos interculturais entre brasileiros e falantes de outros grupos culturais. Certamente, tais estudos contribuirão sobremaneira para o ensino de línguas estrangeiras a falantes brasileiros, para o ensino de português como língua estrangeira a falantes de outras nacionalidades e para um melhor conhecimento de nossas peculiaridades culturais e de como elas afetam nossa produção lingüistica.

\section{O QUE FAZER?}

O simples fato de reconhecer que diferentes padrões culturais determinam diferentes estilos de comunicação e que cada padrāo é perfeitamente adequado para sua comunidade lingüistica já é um grande passo. A próxima etapa seria o estudo sistematizado de tais padrōes comunicativos e sua inclusão nos currículos de cursos que visam à preparação de indivíduos para interações interculturais, como cursos de língua estrangeira, relaçōes públicas, tradutores, intérpretes etc., a fim de sensibilizá-los para a importância de tais fatores na comunicação. Não se trata de fornecerlhes fórmulas de como agir ou falar em um determinado contexto (inter)cultural, mas apenas de despertar sua atenção para a existência de tais padrões comunicativos e para 
uma possivel necessidade de adaptações ou explicações em pontos de divergência.

Para finalizar gostaria de citar uma sugestāo de operacionalização, feita por Kotthoff: a autora enfatiza a idéia de que cursos de lingua estrangeira nāo devem contemplar apenas a transmissāo de vocabulário e gramática da lingua estrangeira, mas também os aspectos socioculturais da comunidade falante dessa lingua, integrandoos nas aulas. Para tanto, sugere que:

Oocupar-se com a cultura estrangeira, suas normas, valores e costumes deve ser incluido na comunicação. Um conceito ampliado de comutnicaçāo exige também a utilizaçāo de meios de comunicaçāo... por exemplo, filmes e videos. Diálogos de filmes podem ser utilizados, por exemplo, para a análise de interaçōes. Pode-se trabalhar cenas inteiras sob pontos de vista da análise lingüistica e cultural e assim iniciar um processo de sensibilização para as especificidades comunicativas da cultura estrangeira (Kotthoff, 1989, p. 458).

\section{BIBLIOGRAFIA}

BROWN, P. \& LEVINSON, S.Universals in Language Usage: Politeness Phenomena. In: GOODY E. N. (Org.) Questions and Politeness - Strategies in Social Interaction. Cambridge, Cambridge University Press, 1978, p. 56-324.

BYRNES, H. Interactional Style in German and American Conversations. Text 6 (2). Amsterdam, de Gruyter, 1986, p. 189-206.

DORNBUSCH, C. S. O olhar estrangeiro. Pandaemonium Germanicum. Revista de Estudos Germânicos 2. São Paulo, Humanitas/FFLCH-USP. 1998.

EHLICH, K. Xenismen und die bleibende Fremdheit des Fremdsprachensprechers. In: HESS-LÜTTICH, E. W B. (Ed.). Integration und Identität. Tübingen, Gunter Narr Verlag, 1986, p. 43-54. 
GENZMER, H. A. K. Mendacity: on contrastive discourse structures in German, English and Spanish. Michigan, University Microfilms International, 1987

GOFFMAN, E. Interaktionsrituale: Über Verhalten in direkter Kommunikation. Frankfurt a.M., Suhrkamp, 1986 (original americano de 1967).

GUMPERZ, J. J \& COOK-GUMPERZ, J. Introduction.

Language and the communication of social identity. In: GUMPERZ, J. J. (Ed.) Language and social identity. Cambridge, Cambridge Univ. Press, 1982, p. 1-21.

GÜNTHNER, S. Diskursstrategien in der interkulturellen Kommunikation. Analysen deutsch-chinesischer Gespräche. Tübingen, Niemeyer, 1993.

HOUSE, J. Interaktionsnormen in deutschen und englischen Alltagsdialogen. Linguistische Berichte 59, 1979, p. 76-90.

\& KASPER, G. Politeness Markers in English and German. COULMAS, F (Org.) Conversational Routine. The Hague/Paris/ New York, Mouton, 1981, p. 157-185.

KOTTHOFF $H$. So nah und doch so fern. Deutsch-amerikanische pragmatische Unterschiede im Universitären Millieu. Info DaF 16, 1989, p. 448-459.

Stilunterschiede in argumentativen Gesprächen oder zum Geselligkeit von Dissens. In: SELTING, M. \& HENNENKAMP V (Org.) Stil und Stilisierung. Tübingen, Niemeyer, 1989(a), p. 187-202.

MEIRELES, S. M. A Dissensão e as Estratégias de Trabalho da Face em diálogos do alemāo. Tese de Doutorado. São Paulo, FFLCH/USP 1997

- A negação sintaticamente explícita em diálogos falados do português e do alemão. Dissertaçāo de Mestrado. Sāo Paulo, FFLCH/USP, 1991.

SPERBER, D. \& WILSON, D. Relevance-Communication and Cognition. Blackwell, Oxford, 1986.

TANNEN, D. Ethnic style in male-female conversation. In: GUMPERZ, J (Ed.) Language and social identity, Cambridge, Cambridge Univ. Press, 1982, p. 217-231. 
148 MEIRELES. Selma Martins. "Por que os estrangeiros sāo estranhos? - como diferenças culturais afetam a comunicação

WEINRICH, H. Lügt man im Deutschen, wenn man höflich ist? Mannheim/Wien/Zürich, Bibliographisches Institut, 1986.

YOUNG, L. W.L. Inescrutability revisted. In: GUMPERZ, J. (Ed.) Language and social identity. Cambridge, Cambridge Univ. Press, 1982, p. 79-83.

\begin{abstract}
In this paper we try to illustrate the importance of cultural conventions that define the conversational style of speakers of a certain language, as well as the difficulties that may occur in intercultural interaction, even when vocabulary and grammar are properly mastered.
\end{abstract}

Keywords: interculturality, cultural conventions, conversational style, German language, Portuguese language. 